\title{
Personality disorders and suicide attempts in unipolar and bipolar mood disorders
}

\section{Jylhä, Pekka}

2016-01-15

Jylhä , P , Rosenstrom , T , Mantere , O , Suominen , K, Melartin , T , Vuorilehto , M , Holma , M , Riihimaki , K , Oquendo , M A , Keltikangas-Jarvinen , L \& Isometsa , E T 2016 , ' Personality disorders and suicide attempts in unipolar and bipolar mood disorders ' , Journal of Affective Disorders, vol. 190 , pp. 632-639 . https://doi.org/10.1016/j.jad.2015.11.006

http://hdl.handle.net/10138/223852

https://doi.org/10.1016/j.jad.2015.11.006

publishedVersion

Downloaded from Helda, University of Helsinki institutional repository.

This is an electronic reprint of the original article.

This reprint may differ from the original in pagination and typographic detail.

Please cite the original version. 
Research report

\title{
Personality disorders and suicide attempts in unipolar and bipolar mood disorders
}

\author{
Pekka Jylhä a,b, Tom Rosenström ${ }^{\text {c }}$, Outi Mantere ${ }^{\mathrm{a}, \mathrm{b}}$, Kirsi Suominen ${ }^{\mathrm{a}, \mathrm{d}}$, Tarja Melartin ${ }^{\mathrm{a}, \mathrm{b}}$, \\ Maria Vuorilehto $^{\mathrm{a}, \mathrm{b}}$, Mikael Holma ${ }^{a}$, Kirsi Riihimäki ${ }^{\mathrm{a}, \mathrm{e}}$, Maria A. Oquendo ${ }^{\mathrm{f}}$, \\ Liisa Keltikangas-Järvinen ${ }^{c}$, Erkki T. Isometsä ${ }^{\text {a,b,* }}$ \\ ${ }^{a}$ Department of Mental Health and Substance Use,National Institute of Health and Welfare, Helsinki, Finland \\ ${ }^{\mathrm{b}}$ University of Helsinki and Helsinki University Hospital, Psychiatry, Helsinki, Finland

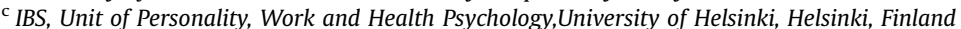 \\ ${ }^{\mathrm{d}}$ City of Helsinki, Social Services and Healthcare, Department of Mental Health and Substance Abuse, Helsinki, Finland \\ e Healthcare and Social Services, City of Järvenpää, Järvenpää, Finland \\ ${ }^{\mathrm{f}}$ Department of Psychiatry, New York State Psychiatric Institute and Columbia University, New York, NY, USA
}

\section{A R T I C L E I N F O}

\section{Article history:}

Received 12 August 2015

Received in revised form

7 October 2015

Accepted 2 November 2015

Available online 10 November 2015

\section{Keywords:}

Suicide attempt

Suicidal behavior

Personality disorders

Mood disorders

Longitudinal studies

\begin{abstract}
A B S T R A C T
Background: Comorbid personality disorders may predispose patients with mood disorders to suicide attempts (SAs), but factors mediating this effect are not well known.

Methods: Altogether 597 patients from three prospective cohort studies (Vantaa Depression Study, Jorvi Bipolar Study, and Vantaa Primary Care Depression Study) were interviewed at baseline, at 18 months, and in VDS and PC-VDS at 5 years. Personality disorders (PDs) at baseline, number of previous SAs, lifecharted time spent in major depressive episodes (MDEs), and precise timing of SAs during follow-up were determined and investigated.

Results: Overall, 219 (36.7\%) patients had a total of 718 lifetime SAs; 88 (14.7\%) patients had 242 SAs during the prospective follow-up. Having any PD diagnosis increased the SA rate, both lifetime and prospectively evaluated, by $90 \%$ and $102 \%$, respectively. All PD clusters increased the rate of new SAs, although cluster C PDs more than the others. After adjusting for time spent in MDEs, only cluster C further increased the SA rate (by 52\%). Mediation analyses of PD effects on prospectively ascertained SAs indicated significant mediated effects through time at risk in MDEs, but also some direct effects. Limitations: Findings generalizable only to patients with mood disorders.

Conclusions: Among mood disorder patients, comorbid PDs increase the risk of SAs to approximately two-fold. The excess risk is mostly due to patients with comorbid PDs spending more time in depressive episodes than those without. Consequently, risk appears highest for PDs that most predispose to chronicity and recurrences. However, also direct risk-modifying effects of PDs exist.
\end{abstract}

(c) 2015 Elsevier B.V. All rights reserved.

\section{Introduction}

Mood and personality disorders carry a significant risk of suicide. Between one-half and two-thirds of all suicides occur in patients with mood disorders (Cavanagh et al., 2003), with lifetime risk of suicide in mood disorders in the 5-6\% range, the risk being somewhat higher in bipolar disorder (BD) than in major depressive disorder (MDD) (Nordentoft et al., 2011). Moreover, comorbid psychiatric disorders increase suicide risk (Nordentoft et al., 2011). Of individuals who die by suicide, $30-40 \%$ of have at least one

\footnotetext{
* Corresponding author at: Department of Psychiatry, University of Helsinki, P.O. Box 22, FI-00014 Helsinki, Finland.

E-mail address: erkki.isometsa@hus.fi (E.T. Isometsä).
}

personality disorder (PD) (Foster et al., 1997; Henriksson et al., 1993) and nearly all of them have also comorbid depressive or substance use disorders, or both (Cheng et al., 1997; Henriksson et al., 1993). Thus, individuals with co-occurring mood and personality disorders comprise the vast majority of all suicides (Foster et al., 1997). Knowing the risk factors for suicide is necessary for rational preventive decisions. However, given suicide's low base rate, much risk factor research has focused on suicide attempts (SAs) as a proxy for suicide. The risk factors for SAs and suicide are mainly similar, although completers are more often males, have more psychotic symptoms, and use more lethal methods (Hawton et al., 2013; Isometsa, 2014).

Risk factors for SAs in mood disorder patients include previous SAs, younger age, hopelessness, impulsive-aggressive traits, poor perceived social support, and concurrent anxiety, substance use, 
Table 1

Methods used in the Jorvi Bipolar Study (JoBS), the Vantaa Depression Study (VDS), and the Vantaa Primary Care Depression Study (PC-VDS).

\begin{tabular}{|c|c|c|c|}
\hline Cohort & JoBS & VDS & PC-VDS \\
\hline Timing of screening & Jan 1, 2002 to Feb 28, 2003 & Feb 1, 1997 to May 31, 1998 & Jan 1, 2002 to Dec 31, 2002 \\
\hline Catchment area & $\begin{array}{l}\text { Adjacent cities of Espoo, Kauniainen, } \\
\text { and Kirkkonummi (population } 261100 \\
\text { in 2002) }\end{array}$ & City of Vantaa (population 169000 in 1997) & $\begin{array}{l}\text { Two districts in the city of Vantaa (popu- } \\
\text { lation of } 63,400 \text { in 2002) }\end{array}$ \\
\hline Setting & $\begin{array}{l}\text { Department of Psychiatry, Jorvi Hospi- } \\
\text { tal, Helsinki University Central Hospital, } \\
\text { Espoo, Finland }\end{array}$ & $\begin{array}{l}\text { Department of Psychiatry of the Peijas Medical } \\
\text { Care District, Helsinki University Central Hospital, } \\
\text { Vantaa, Finland }\end{array}$ & $\begin{array}{l}\text { Primary Health Care Organization of the } \\
\text { City of Vantaa, Finland } \\
\text { Three health centers } \\
\text { Two maternity clinics served by } 30 \text { gen- } \\
\text { eral practitioners with population-based } \\
\text { responsibility }\end{array}$ \\
\hline Target group & $\begin{array}{l}\text { All psychiatric patients aged } 18-59 \\
\text { years } \\
\text { (1) seeking treatment } \\
\text { (2) referred to treatment, or } \\
\text { (3) already in treatment with an acute } \\
\text { deteriorating clinical state }\end{array}$ & $\begin{array}{l}\text { All psychiatric patients aged } 20-59 \text { years } \\
\text { (1) seeking treatment } \\
\text { (2) referred to treatment, or } \\
\text { (3) already in treatment with an acute dete- } \\
\text { riorating clinical state }\end{array}$ & $\begin{array}{l}\text { Consecutive primary care patients aged } \\
20-59 \text { years in general practitioners' } \\
\text { waiting room }\end{array}$ \\
\hline Exclusion from screening & ICD-10 schizophrenia & ICD-10 schizophrenia, BD I & $\begin{array}{l}\text { Poor general health status prohibiting } \\
\text { completion of screening form }\end{array}$ \\
\hline Screening procedure & $\begin{array}{l}\text { (1) Mood Disorders Questionnaire, 7/ } \\
13 \text { items positive, or } \\
\text { (2) Clinical suspicion of } \mathrm{BD}(\mathrm{N}=28)\end{array}$ & $\begin{array}{l}\text { (1) Five screening questions for depression from } \\
\text { SCAN, } 1 \text { positive, or } \\
\text { (2) Scale for Suicide Ideation, score } \geq 6\end{array}$ & $\begin{array}{l}\text { (1) PRIME-MD: positive answer to either } \\
\text { question concerning depressed mood } \\
\text { or anhedonia during the past month, } \\
\text { and } \\
\text { (2) Telephone interview: one or more } \\
\text { main symptoms of depression accord- } \\
\text { ing to SCID-I/P }\end{array}$ \\
\hline Total screened & 1630 & 806 & $1111(8$ refused $)$ \\
\hline Screened positive & 546 & 703 & 402 \\
\hline Refusals & Screening 46 ( $2.8 \%$ of all screened), In- & $161(22.9 \%)$ & $37(9.2 \%)$ \\
\hline
\end{tabular}

Diagnostic interview

Inclusion criteria

Cohort

Current psychiatric comorbidity

Number of patients at 6-month follow-up

18-month follow-up Number of patients

Participants vs. nonparticipants

Mean time for interview

5-year follow-up Number of Patients

Switch of diagnosis

Participants vs. nonparticipants

Mean time for interview

Number of patients with follow-up data from at least one follow-up interview

Diagnostic reliability at baseline terview 49 ( $9.0 \%$ of positive screens)

After informed consent, DSM-IV (SCID- After informed consent, DSM-IV (Axis I, SCAN) I/P and SCID-II)

DSM-IV type I or II with a new depressive, manic, hypomanic, mixed, or depressive mixed episode of BD 191 MDD patient with a current epioutpatients)

Anxiety Disorder $44.5 \%$

Substance Use Disorder 19.9\%

Eating Disorder 7.9\%

Somatoform Disorder 5..2\%

Personality Disorder $42.9 \%$

1. Cluster A $9.9 \%$

2. Cluster B $24.6 \%$

3. Cluster C $23.0 \%$

176 (92.1\%)

$161(84.3 \%)$

DSM-IV MDD with a new depressive episode

269 BD patient with a current phase at baseline

(46 inpatients, 223 outpatients)

Anxiety Disorder 57\%

Alcohol Use Disorder 25\%

Bulimia Nervosa 2\%

Personality Disorder 44\%

1. Cluster A $19.0 \%$

2. Cluster B $14.5 \%$

3. Cluster C $31.6 \%$

$229(85.1 \%)$

198 (77.3\%)

After informed consent DSM-IV (SCID-I/P and SCID-II)

DSM-IV unipolar depressive disorders with no current treatment in psychiatric care

137 outpatients from primary care; 91 MDD patients with current episode and 46 patients with subsyndromal depression at baseline

Anxiety Disorder 43\%

Substance Use Disorder 12\%

Somatoform Disorder $12 \%$

Eating Disorder 2\%

Personality Disorder 52\%

1. Cluster A $1.0 \%$

2. Cluster B $28.0 \%$

3. Cluster C $32.0 \%$

$92(88.5 \%)$

Somewhat older (mean 39.0 years, SD 11.9 vs. 33.7 years, SD 12.1, $t=2.711$,

$\mathrm{df}=189, p=0.007$ )

$19.8 \pm 3.0$ months $-$

$182(67.7 \%)$

$112(82.0 \%)$

29 BD, 1 schizophrenia, 2 schizoaffective disorder 5 BD More often female ( $72.1 \%$ vs. $55.6 \%, \chi^{2}=6.581$, $p=0.010$ ), married or cohabiting ( $75.6 \%$ vs. $59.7 \%$ $\left.\chi^{2}=7.725, p=0.005\right)$, less alcohol dependence at baseline (39.5\% vs. $72.3 \%, \chi^{2}=16.064, p<0.001$ ) 5.2 years

249

No difference in age, gender, or baseline depression severity

\section{2 years}

176

20 videotaped diagnostic interviews; kappa coefficient for $\mathrm{BD}=1.0$; not tested for comorbidity

20 videotaped diagnostic interviews; kappa coefficient for current $\mathrm{MDD}=0.86(95 \% \mathrm{CI}=$ 0.58-1.00); not tested for comorbidity

20 videotaped diagnostic interviews: kappa coefficient for current MDD and current subsyndromal diagnoses $=1.0$; not tested for comorbidity

By interview and medical and psychiatric records By interview and medical and psychiatric at baseline and at 6- and 18-months and at 5-years

HAM-D, BDI, BAI (baseline, 18 months, and 5 years). Psychotic symptoms as part of semistructured interview records at baseline and at 18 -months and at 5-years

HAM-D, BDI, BAI (baseline, 18 months, and 5 years). Psychotic symptoms as part of semistructured interview
18 months). Psychotic symptoms as part of semistructured interview. 
Table 1 (continued)

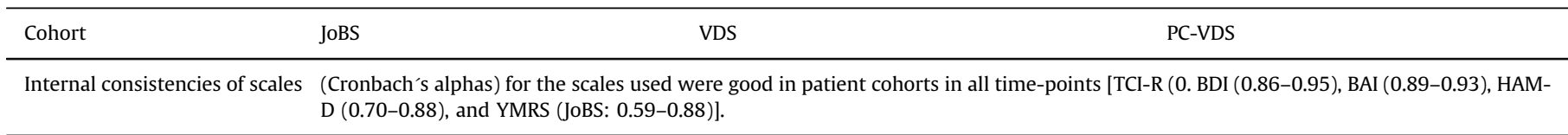

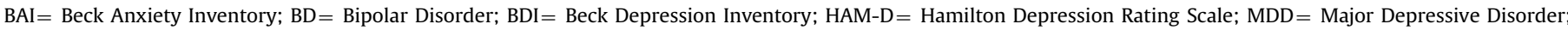

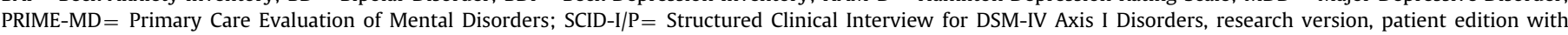

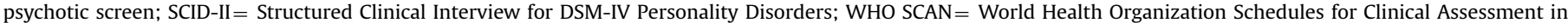
Neuropsychiatry, version 2.0; YMRS= Young Mania Rating Scale

and PD (for reviews, see (Beghi et al., 2013; Hawton et al., 2013; Isometsa, 2014)). Multiple interacting risk (e.g. above mentioned) and protective (e.g. meaningful and important relationships) factors influence suicidal behavior (Mann et al., 1999). However, in prospective studies (Holma et al., 2010, 2014; Riihimaki et al., 2014a; Valtonen et al., 2008) we have shown that a major determinant, with a consistently high population-attributable fraction, is the time spent in high-risk illness phases. Compared with euthymia, the incidence of SAs during major depressive phases is 25-fold and during mixed illness episodes in BD 65-fold (Holma et al., 2014). Among patients with mood disorders, suicidal acts in the absence of an illness episode are rare (Holma et al., 2010, 2014; Riihimaki et al., 2014a; Valtonen et al., 2008). Both comorbid DSMIV cluster B (Skodol et al., 2011) and C (Oleski et al., 2012) PDs have been shown to increase time that an individual spends in major depressive episodes (MDEs).

The relationship between mood disorder and comorbid PDs and SAs has been investigated in longitudinal epidemiological (Bolton et al., 2010; Oleski et al., 2012) and clinical (Galfalvy et al., 2006; Oquendo et al., 2007; Stringer et al., 2013; Undurraga et al., 2012) studies among mood disorder patients and in longitudinal clinical studies among PD patients (Soloff and Chiappetta, 2012; Yen et al., 2003). In these studies, cluster B PDs, especially borderline PD, have been established as a risk factor for SAs, whereas cluster $A$ and $C$ PDs have received less attention. The most consistent predictors for a future SA have been borderline PD comorbid with MDD (Bolton et al., 2010; Soloff and Chiappetta, 2012; Soloff and Fabio, 2008; Yen et al., 2003), BD with current MDE (Galfalvy et al., 2006), and both MDD and BD with current MDE (Oquendo et al., 2007) or dysthymia (Stringer et al., 2013). Also baseline cluster C (Oleski et al., 2012), dependent (Bolton et al., 2010), avoidant (Bolton et al., 2010), paranoid (Bolton et al., 2010), schizoid (Bolton et al., 2010), schizotypal (Bolton et al., 2010), or any (Bolton et al., 2010; Undurraga et al., 2012) PD comorbid with MDD or MDE in BD patients has been associated with higher rates of SAs at follow-up. A number of other risk factors e.g. sociodemographic factors, number of depressive symptoms, other comorbid disorder, previous suicidal behavior have been controlled in the aforementioned studies, but not the proportion of time spent in MDEs during the follow-up; yet, it is a key predictor of accumulated risk for suicidal acts (Holma et al., 2010, 2014; Riihimaki et al., 2014a; Valtonen et al., 2008).

In this prospective cohort study of mood disorder patients, we aimed to investigate the relationship between comorbid PDs and future SAs. We hypothesized that 1 ) baseline comorbid cluster C and borderline PDs would increase the rate of SAs indirectly by increasing time spent in MDEs. Moreover, 2) we expected that borderline PD would also (directly) modify the risk of SAs during MDEs.

Therefore, we investigated the relationship between comorbid PD and 1) lifetime (total retrospective and prospective) SAs and 2) prospectively evaluated new SAs during the follow-up. We also tested 3) whether comorbid PD acts directly on the rate of SAs or indirectly by increasing the duration of MDEs during the followup. In analyses of prospectively evaluated SAs, we 4) controlled for confounding sociodemographic and clinical risk factors. Finally, we conducted formal mediation analyses.

\section{Methods}

Patients came from three separate but comparable cohorts (Jorvi Bipolar Study, JoBS; Vantaa Depression Study, VDS; Vantaa Primary Care Depression Study, PC-VDS), collaborative research projects of the Mood Disorder Research Unit of the Department of Mental Health and Substance Use of the National Institute of Health and Welfare, Helsinki, Finland (Principal Investigator EI). The pertinent ethics committee approved the research protocols. The detailed methodologies have been described elsewhere for JoBS (Mantere et al., 2004, 2008), VDS (Holma et al., 2008; Melartin et al., 2002), and PC-VDS (Riihimaki et al., 2014b; Vuorilehto et al., 2005) (see also Table 1).

\subsection{Screening and baseline evaluation}

Altogether 3555 primary care or psychiatric patients were screened for acute phase of unipolar depressive disorder (PC-VDS) or BD (JoBS) or MDD (VDS). Patients were fully informed about the study and gave written informed consent. Diagnoses were based on semistructured interviews (Table 1). Most of the interviewers were psychiatrists or doctors specializing in psychiatry and two experienced clinical psychologists. In PC-VDS, two-thirds of the patients had MDD, and the rest had dysthymia, currently subsyndromal but lifetime MDD, or true minor depression. The final baseline cohorts included 191 DSM-IV BD I and II patients (JoBS), 269 MDD patients (VDS), and 137 unipolar depressive disorder patients (PC-VDS). Interrater agreement in diagnostic interviews was excellent (kappa 0.86-1.00) (Mantere et al., 2008; Melartin et al., 2002; Riihimaki et al., 2014b).

Full DSM-IV axis I diagnoses (Structured Clinical Interview for DSM-IV Disorders, SCID-I/P (First et al., 2002) in JoBS and PC-VDS; Schedules for Clinical Assessment of Neuropsychiatry, SCAN (Wing et al., 1990) in VDS) and axis II diagnoses (Structured Clinical Interview for DSM-IV Personality Disorders, SCID-II for DSM-IV (First et al., 1997) in JoBS and PC-VDS; SCID-II for DSM-III-R in VDS) were made. Prevalence of comorbid psychiatric diagnoses are mentioned in Table 1. Information was also gathered on demographic characteristics, current symptomatology using the 17-item Hamilton Depression Scale, HAM-D (Hamilton, 1960), the 21-item Beck Depression Scale, BDI (Beck et al., 1961), the 21-item Beck Anxiety Scale, BAI (Beck et al., 1988), and the Young Mania Rating Scale, YMRS (Young et al., 1978), and illness history using a retrospective life-chart.

\subsection{Follow-up}

After baseline assessments, patients were interviewed at 6 (JoBS and VDS) and 18 (JoBS, VDS, and PC-VDS) months and at 5 years (VDS and PC-VDS). Repeated SCID-I/P (JoBS and PC-VDS at all follow-ups, and VDS at 5 years), SCAN 2.0 (VDS at 18 months), 
Table 2

Baseline sociodemographic and clinical characteristics and mean scores and standard deviations (SD) of Beck Depression Inventory (BDI), Beck Anxiety Disorder (BAI), Hamilton Rating Scale for Depression (HAM-D), and Perceived Social Support Scale - Revised (PSSS-R) of patients with $(n=219)$ or without $(n=378)$ lifetime suicide attempt (SA).

\begin{tabular}{|c|c|c|c|c|c|c|}
\hline & \multicolumn{2}{|c|}{$\begin{array}{l}\text { Patients with } \\
\text { lifetime SA } \\
(n=219)\end{array}$} & \multicolumn{2}{|c|}{$\begin{array}{l}\text { Patients without } \\
\text { lifetime SA } \\
(n=378)\end{array}$} & \multirow[b]{2}{*}{$\chi^{2}$} & \multirow[b]{2}{*}{$\mathrm{p}$} \\
\hline & $\mathrm{n}$ & $\%$ & $\mathrm{n}$ & $\%$ & & \\
\hline Gender & & & & & & ns \\
\hline Female & 155 & 70.8 & 247 & 65.3 & & \\
\hline Male & 64 & 29.2 & 131 & 34.7 & & \\
\hline Education $^{a}$ & & & & & & ns \\
\hline $\begin{array}{l}\text { University or } \\
\text { polytechnic }\end{array}$ & 70 & 32.2 & 150 & 37.7 & & \\
\hline Vocational & 52 & 24.0 & 93 & 25.1 & & \\
\hline None & 95 & 43.8 & 138 & 37.2 & & \\
\hline Marital status ${ }^{\mathrm{b}}$ & & & & & 4.354 & 0.037 \\
\hline $\begin{array}{l}\text { Married or } \\
\text { cohabiting }\end{array}$ & 94 & 43.1 & 194 & 52.0 & & \\
\hline Single & 124 & 56.9 & 179 & 48.0 & & \\
\hline Work status ${ }^{\mathrm{c}}$ & & & & & & ns \\
\hline Employed & 147 & 68.1 & 259 & 69.4 & & \\
\hline Unemployed & 69 & 31.9 & 114 & 30.6 & & \\
\hline $\begin{array}{l}\text { Comorbid disorders } \\
\text { evaluated at } \\
\text { baseline }\end{array}$ & & & & & & \\
\hline Any anxiety disorder & 125 & 57.1 & 171 & 45.2 & 7.775 & 0.005 \\
\hline $\begin{array}{l}\text { Alcohol dependence, } \\
\text { current }\end{array}$ & 33 & 15.1 & 38 & 10.1 & & ns \\
\hline $\begin{array}{l}\text { Any personality dis- } \\
\text { order, current }\end{array}$ & 121 & 55.3 & $150^{\mathrm{d}}$ & 39.7 & 13.559 & $<0.001$ \\
\hline Cluster A & 32 & 14.6 & $45^{\mathrm{d}}$ & 11.9 & & ns \\
\hline Paranoid & 27 & 12.3 & $44^{\mathrm{d}}$ & 11.7 & & ns \\
\hline Schizoid & 5 & 2.3 & $1^{\mathrm{d}}$ & 0.3 & 5.660 & 0.017 \\
\hline Schizotypal & 2 & 0.9 & $0^{\mathrm{d}}$ & 0 & & ns \\
\hline Cluster B & 67 & 30.6 & $65^{d}$ & 17.2 & 14.323 & $<0.001$ \\
\hline Histrionic & 3 & 1.4 & $6^{\mathrm{d}}$ & 1.6 & & ns \\
\hline Narcissistic & 4 & 1.8 & $10^{\mathrm{d}}$ & 2.7 & & ns \\
\hline Borderline & 63 & 28.8 & $54^{\mathrm{d}}$ & 14.3 & 18.317 & $<0.001$ \\
\hline Antisocial & 8 & 3.7 & $6^{\mathrm{d}}$ & 1.6 & 2.566 & ns \\
\hline Cluster C & 78 & 35.6 & $95^{\mathrm{d}}$ & 25.2 & 7.297 & 0.007 \\
\hline Avoidant & 57 & 26.0 & $56^{\mathrm{d}}$ & 14.9 & 11.256 & 0.001 \\
\hline Dependent & 15 & 6.8 & $14^{\mathrm{d}}$ & 3.7 & & ns \\
\hline $\begin{array}{l}\text { Obsessive- } \\
\text { Compulsive }\end{array}$ & 24 & 11.0 & 32 & 8.5 & & ns \\
\hline \multirow{2}{*}{$\begin{array}{l}\text { Psychotic features, } \\
\text { lifetime }\end{array}$} & 82 & 37.4 & 62 & 16.4 & 33.541 & $<0.001$ \\
\hline & Mean & SD & Mean & SD & $\mathrm{t}$ & $\mathrm{p}$ \\
\hline Age & 38.8 & 12.2 & 41.2 & 12.4 & 2.241 & 0.025 \\
\hline BDI & 27.1 & 11.1 & 22.6 & 10.0 & -5.166 & $<0.001$ \\
\hline BAI & 24.2 & 12.5 & 19.4 & 11.3 & -4.782 & $<0.001$ \\
\hline HAM-D & 16.0 & 7.3 & 13.1 & 5.9 & -5.305 & $<0.001$ \\
\hline PSSS- $R^{e}$ & 42.0 & 12.6 & 43.2 & 12.6 & & ns \\
\hline
\end{tabular}

a missing data $2 / 219,7 / 378$,

b missing data $1 / 219,5 / 378$,

c missing data $3 / 219,5 / 37$,

d missing data $1 / 378$

and SCID-II interviews and all observer- and self-reported symptom scales were included at all follow-up assessments. Course of illness was documented on a prospective life-chart based on DSMIV criteria (Holma et al., 2008; Mantere et al., 2008; Riihimaki et al., 2014b; Vuorilehto et al., 2009). Criteria for hypomania were as in the DSM-IV, except duration of at least 2 days. Sociodemographic characteristics are presented in Table 2.

\subsection{Suicide attempts}

A suicide attempt was defined as a self-injurious behavior with non-fatal outcome accompanied by evidence that the person had at least some degree of intent to die (APA, 2003; Holma et al., 2010, 2014; Riihimaki et al., 2014a; Valtonen et al., 2008). At baseline, information about previous SAs was obtained by interviews and psychiatric records. Information regarding SAs during follow-up was based on both patient interview and psychiatric and general medical records. During follow-up we assessed episodes of depression and SAs independently by questioning the patients first about their life events and mood, and then about SAs, to avoid automatically attributing the disorders to each other or the acts to the episode.

\subsection{Study design}

We examined whether baseline comorbid PDs predicted number of prospectively ascertained SAs at follow-up or were associated with number of lifetime (including prospective) attempts. Formal mediation tests were conducted for all three PD clusters and for specific PDs on SA risk. For further methodological details, see Supplementary materials.

\subsection{Statistical methods}

The statistical data analyses were conducted using R-software, 64-bit Linux version 2.15.3. Poisson regression was applied in modeling the number of SAs per month (participant-specific 'offset' for the time of exposure) as a function of independent variables (see online supplementary materials for further details). Overdispersal was present when studying lifetime attempts (dispersion test in "AER" R-package version 1.2-1), and thus, quasiPoisson models were used for this outcome (Cameron and Trivedi, 1990). Missing data were modeled using Multiple Imputation by Chained Equations (see online supplement), and imputed results are presented along with a non-imputed sensitivity analysis (van Buuren and Groothuis-Oudshoorn, 2011). As a further sensitivity analysis, we studied whether PDs were differentially associated with having attempted suicide (status) versus the number of attempts. The status outcome of having attempted suicide or not was modeled using Logistic Regression models. The possible mediating role of depressive episodes between PD and SA was studied using "mediation" R-package (version 4.4.3), with a linear regression model for time spent in MDEs, a Poisson regression model for number of SAs, and a logistic regression for attempterstatus outcome (Imai et al., 2010). For a statistical power analysis, see the online supplement.

\section{Results}

In total, 219 (36.7\%) patients had had one or more lifetime (total retrospective and prospective) SAs, whereas $88(14.7 \%)$ patients made one or more attempts during their life-charted followup period. Total number of lifetime SAs in the whole sample was 718 (mean=1.20; s.d.=2.79). Altogether 242 new attempts were observed during the follow-up period, with the average rate of new attempts being 0.018 attempts/month (s.d. $=0.074$ ).

\subsection{Personality disorders in relation to suicide attempt rates}

Participants with any PD diagnosis at baseline had a 90\% increase in the rate of lifetime SAs, and a $102 \%$ increase in prospectively observed SAs relative to participants without PDs. Even during the high-risk state of MDE, presence of any PD increased the rate of a new SA by $39 \%$ and a cluster C disorder nearly doubled (90\% increase) the SA rate. See Table 3 for results for all PD clusters, for borderline PD specifically, and, as a reference, also for previous attempt.

A post-hoc analysis of the cluster $C$ diagnoses revealed that avoidant PD (81.5\% increased rate of SAs [95\% CI $=22.0 \%, 168.0 \%])$ 
Table 3

Personality disorder-associated increases in suicide attempt (SA) rates.

\begin{tabular}{|c|c|c|c|c|c|c|c|c|}
\hline \multirow[b]{2}{*}{ Variable } & \multicolumn{4}{|l|}{ Lifetime SAs ${ }^{\mathrm{a}}$} & \multicolumn{4}{|l|}{ New SAs ${ }^{\mathrm{b}}$} \\
\hline & Increase (\%) & low CI & high CI & $n$ & Increase (\%) & low CI & high CI & $n$ \\
\hline Any PD & 90.4 & 30.3 & 181.2 & 596 & 101.6 & 53.7 & 166.4 & 554 \\
\hline Cluster A & 35.7 & -21.8 & 122.4 & 596 & 68.3 & 21.5 & 128.8 & 554 \\
\hline Cluster B & 99.4 & 35.4 & 191.0 & 596 & 67.4 & 25.7 & 121.7 & 554 \\
\hline Cluster C & 88.1 & 29.6 & 171.0 & 596 & 122.2 & 71.6 & 188.1 & 554 \\
\hline Borderline PD & 120.6 & 49.2 & 222.7 & 596 & 79.5 & 33.9 & 138.9 & 554 \\
\hline \multirow[t]{3}{*}{ Previous attempt } & - & - & - & & 227.0 & 150.3 & 327.7 & 555 \\
\hline & \multicolumn{4}{|c|}{ New attempts during MDE $^{\mathrm{C}}$} & \multicolumn{4}{|c|}{ New attempts, multiple imputation ${ }^{\mathrm{d}}$} \\
\hline & Increase (\%) & low CI & high CI & $n$ & Increase (\%) & low CI & high CI & $n$ \\
\hline Any PD & 38.9 & -6.9 & 110.9 & 451 & 101.5 & 53.1 & 165.2 & 555 \\
\hline Cluster A & 26.3 & -19.3 & 92.6 & 451 & 68.3 & 22.7 & 130.8 & 555 \\
\hline Cluster B & 31.8 & -11.7 & 95.2 & 451 & 67.3 & 26.0 & 122.2 & 555 \\
\hline Cluster C & 89.9 & 29.9 & 179.3 & 451 & 122.1 & 71.5 & 187.8 & 555 \\
\hline Borderline PD & 33.3 & -11.0 & 97.7 & 451 & 79.3 & 34.3 & 139.5 & 555 \\
\hline Previous attempt & 130.6 & 53.1 & 246.8 & 452 & 227.0 & 148.5 & 330.4 & 555 \\
\hline
\end{tabular}

$\mathrm{PD}=$ personality disorder; $\mathrm{CI}=95 \%$ confidence interval; $n=$ sample size; $\mathrm{MDE}=$ major depressive disorder.

${ }^{a}$ Estimates for lifetime suicide attempt rates are from the quasi-Poisson regression model, adjusted for age, sex, and sampling cohort by additional indicator covariates. Missing PD data $1 / 597$.

${ }^{\mathrm{b}}$ Estimates for new suicide attempt rates are from the Poisson regression model, adjusted for age, sex, sampling cohort, an indicator for having attempted suicide

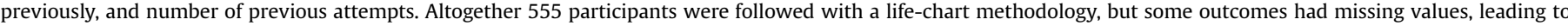
smaller analytic sample sizes.

c The analysis for new SAs was repeated for new attempts during MDE, using time spent in MDE as the exposure instead of total follow-up time. Patients without MDEs were excluded.

d The analysis for new SAs was repeated using multiple imputation of missing variables for those participants that had a life-charted period of exposure.

Cluster $\mathrm{A}(\mathrm{m}=73 \%)$

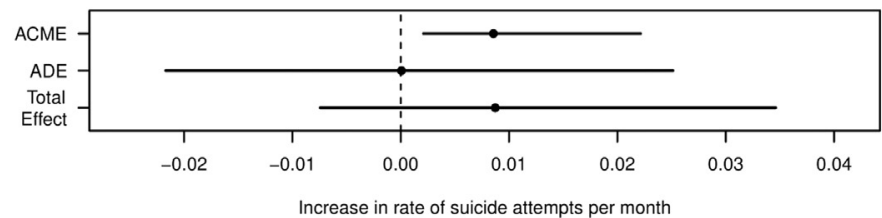

Cluster $\mathrm{C}(\mathrm{m}=\mathbf{4 5} \%)$

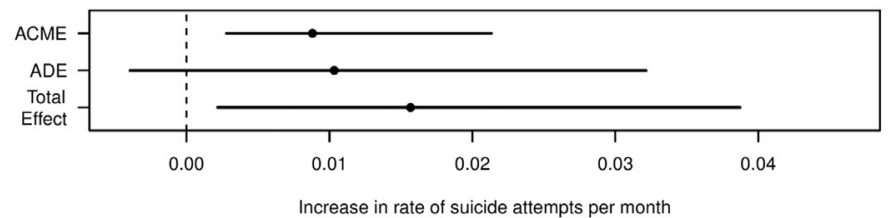

Cluster A $(m=\mathbf{5 0} \%)$

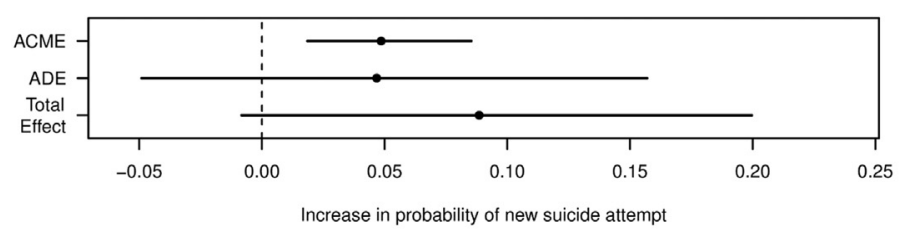

Cluster $\mathrm{C}(\mathrm{m}=68 \%)$

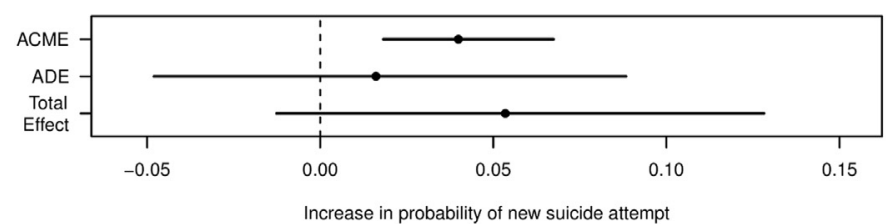

Cluster B (m = 83\%)

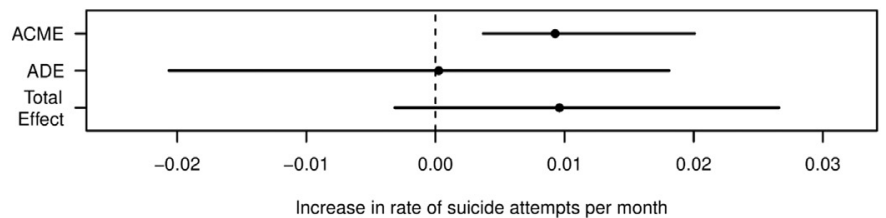

Borderline PD $(m=94 \%)$

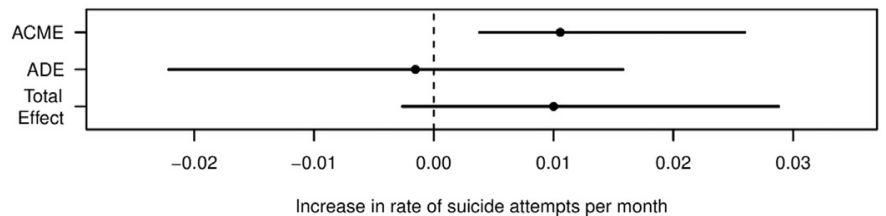

Cluster $B(m=91 \%)$

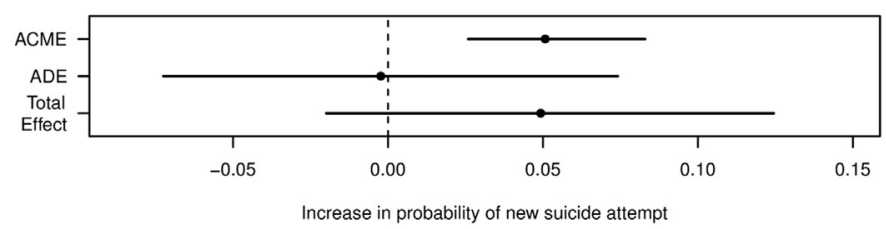

Borderline PD $(m=100 \%)$

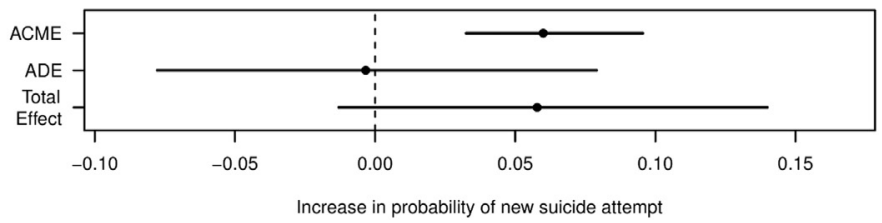

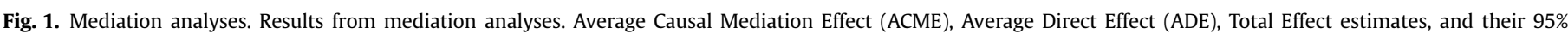

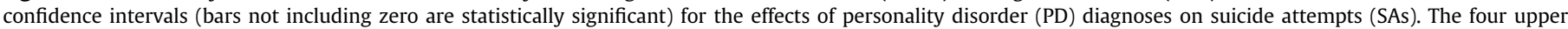

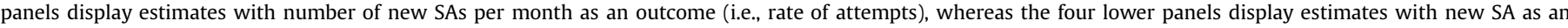
outcome (i.e., attempter status). $\mathrm{m}=$ Proportion of PD effects on a new SA mediated by time spent in major depressive episodes (details in supplementary material). 
and dependent PD (91.7\% [95\% CI=14.6\%, 207.0\%]) contributed to the effect, whereas obsessive-compulsive PD did not (8.2\% [95\% $\mathrm{CI}=-38.9 \%, 79.7 \%])$. Among all new SAs, not just those during MDE, having an avoidant $(n=108)$ or dependent $(n=26)$ PD increased the rate of attempts by $165 \%$ (95\% $\mathrm{CI}=104.2 \%, 244.7 \%$ ). Contrary to our expectations, borderline PD appeared less important in new SAs than cluster C (Table 3). The results did not change in a sensitivity analysis examining VDS and JoBS patients without the borderline PD suicidality item. Online Supplementary analysis provides a breakdown of borderline PD symptoms in relation to new SAs, showing that the number of symptoms lacked a clear dose-response relationship with SA rate, whereas the avoidant PD symptoms did have a dose-response effect on risk for SA. Of borderline PD symptoms, identity disturbance was the only predictor of new SAs, after adjusting for age, sex, having had a previous suicide attempt, and number of previous attempts (in detail in Supplementary material).

\subsection{Mediating role of depressive episodes}

We assessed whether the time spent in MDEs during the follow-up mediated the effects of PDs on new SAs (Fig. 1). The effects of cluster B and borderline PD on both SA rate and probability of a new SA were clearly mediated by the time spent in MDEs. Cluster $C$ appeared to have mediated effects, with possible but non-significant direct effects on SAs as well. Cluster A's effects on SA rates were similarly mediated by the time spent in MDEs, with some non-significant indications for possible direct effects only when SAs were analyzed categorically.

\subsection{Other risk factors and subgroups}

We adjusted the PD-SA associations for several potential confounders and also evaluated them in relevant subgroups (Table 4).

\section{Table 4}

Personality disorder-associated increases (\%) in rate of new suicide attempts (SA) under further adjustments and sensitivity analyses with multiple imputation $(n=555)$.

\begin{tabular}{|c|c|c|c|c|c|}
\hline Adjusted variable & Any PD & Cluster A & Cluster B & Cluster C & Borderline \\
\hline $\begin{array}{l}\text { Original findings (for } \\
\text { reference) }\end{array}$ & $101.5^{* * *}$ & $68.3^{* *}$ & $67.3^{* * * *}$ & $122.1^{* * *}$ & $79.3^{* * *}$ \\
\hline Time spent in MDE & 28.3 & -0.3 & 2.1 & $52.3^{* *}$ & 3.0 \\
\hline BDI & $77.5^{* * * *}$ & $55.1^{* *}$ & $42.9^{*}$ & $97.0^{* * *}$ & $51.9^{* * *}$ \\
\hline BAI & $74.0^{* * * *}$ & $49.0^{*}$ & $43.5^{*}$ & $96.0^{* * * *}$ & $53.8^{* *}$ \\
\hline Psychotic symptoms & $95.0^{* * * *}$ & $60.0^{* * *}$ & $66.3^{* * *}$ & $113.0^{* * *}$ & $75.3^{* * *}$ \\
\hline Hopelessness & $75.6^{* * *}$ & $39.9^{\prime \prime}$ & $47.9^{* *}$ & $101.3^{* * *}$ & $55.3^{* *}$ \\
\hline Social support & $56.1^{* *}$ & 23.0 & 32.6 & $97.2^{* * *}$ & 40.6 \\
\hline Married & $97.5^{* * * *}$ & $67.7^{* *}$ & $66.0^{* * * *}$ & $119.9^{* * *}$ & $75.6^{* * *}$ \\
\hline Substance use & $88.8^{* * *}$ & $61.4^{* *}$ & $55.2^{* *}$ & $108.8^{* * *}$ & $67.9^{* * *}$ \\
\hline \multicolumn{6}{|l|}{ Subsample } \\
\hline $\begin{array}{l}\text { Depressed only } \\
\qquad(n=379)\end{array}$ & $84.3^{* * *}$ & $91.2^{* * *}$ & $101.2^{* * * *}$ & $104.2^{* * * *}$ & $112.5^{* * *}$ \\
\hline $\begin{array}{l}\text { Bipolars only } \\
\quad(n=176)\end{array}$ & $156.1^{* * * *}$ & 18.6 & 28.9 & $146.5^{* * *}$ & 35.0 \\
\hline $\begin{array}{l}\text { Primary-care de- } \\
\text { pressed only } \\
(n=130)\end{array}$ & 82.6 & 38.2 & 98.2 & 113.2 & 110.1 \\
\hline
\end{tabular}

$\mathrm{PD}=$ personality disorder; $\mathrm{MDE}=$ major depressive episode; $\mathrm{BDI}=$ Beck's depression inventory; $\mathrm{BAI}=$ Beck's Anxiety inventory; Adjusted variables refer to additional adjusting of Poisson regression model with the indicated covariate, other covariates being age, sex, having had a previous SA, number of previous SAs, and the diagnosis indicated by the column. The estimate shown is for the increase in rate of new SAs due to having the diagnosis at the baseline assessment. Original findings (first row) without additional covariates are shown for reference, and the rows under the heading "Subsample" refer to these analyses re-computed in the indicated subsample.

${ }^{*} p$-Value less than 0.05 ;

" $p$-Value less than 0.01 ;

$p$-Value less than 0.001 .
As expected from the mediation analysis, adjusting for the time spent in MDEs attenuated all predictive effects for the rate of new SAs, excluding the one for cluster C PD. In addition, the original findings for clusters $\mathrm{A}$ and $\mathrm{B}$ were non-significant in BD patients and were attenuated by adjusting for social support in all patients (Table 4). Because the lack of studies on suicidality of primary care patients has been emphasized (Hawton et al., 2013), we also presented a subsample analysis of the small primary care sample $(n=130)$. Despite low statistical power, the qualitative findings were similar to those for the total sample.

\section{Discussion}

Personality disorders have been known to increase mood disorder patients' risk of suicide attempts, but the reasons for this have remained unclear. We investigated the relationship between personality disorders (PDs) and suicide attempts (SAs) in three prospectively studied mood disorder cohorts, finding the risk of SAs to be generally two-fold among patients with a PD. A main finding was that the influence of an individual's PD on SA risk was mostly indirect, mediated by increased time spent in high-risk states, i.e. major depressive episodes (MDEs). However, PDs also had some direct risk-modifying effects on SA rate during depressive episodes; the best evidence for such influences emerged for cluster C PDs.

This study has numerous methodological strengths. To our knowledge, this is the first study evaluating whether the increased suicidal behavior among PD patients could be explained (mediated) by their greater time at risk (in depressive states) relative to other patients. Information on SAs was gathered both retrospectively and prospectively during the follow-up, with consistent findings of risk factors in both time-frames. The most important strength was availability of prospectively collected life-charts with information on illness course and timing of SAs, allowing testing of mediator hypotheses. Patients were assessed prospectively with semistructured interviews with excellent interrater reliability and both objective and subjective structured and semistructured measures. Information regarding all comorbid axis I and II disorders at baseline was also available. Besides comorbid axis II disorders, we investigated a broad range of risk and protective factors from several domains, including axis I comorbid disorders and symptoms, history of suicidal behavior, and psychosocial factors, on the risk of SAs. All cohorts employed similar methodology, allowing valid comparisons and pooling of data.

Nevertheless, some limitations also exist. The lengths of followups differed, as the five-year follow-up data from the JoBS were not yet available at the time of analysis. The data were therefore modeled in Poisson regressions using the standard offset, or length-of-exposure, term. Second, similarly to any study including a retrospective evaluation, recall bias is possible, and depression might affect recall of previous SAs. Third, although no specific scale for the assessment of SAs was used (e.g the Suicide Intent Scale, Beck et al., 1974), the evaluation of the rate of new SAs was probably not over- or underestimated due to the thorough interviews, typically lasting 2-3 h and the life chart methodology used. Fourth, it was only possible to investigate time spent in crudely classified risk states instead of detailed temporal tracking of individual-specific risk states. Risk for attempts likely covaries significantly with levels of depression, hopelessness, and possibly anxiety, none of which were measured on a daily or moment-tomoment basis. Thus, the observed gradient between symptom states (Holma et al., 2010, 2014; Riihimaki et al., 2014a; Valtonen et al., 2008) is likely an underestimate. Fifth, sample sizes restricted the accuracy of estimates. Sixth, the study was naturalistic, and treatments for mood disorders were not controlled, although 
they may influence both the time ill and the risk for SAs. How often comorbid personality disorders were clinically recognized and whether treatments were focused on them remain unknown. Seventh, the SCID-II interviews were based on DSM-IV in PC-VDS and JoBS, but DSM-III-R in VDS. There are also minor differences in PD diagnostic criteria between DSM-III-R and DSM-IV. Eigth, the diagnostic criteria for borderline PD include suicidal behavior, which to the degree that past "recurrent suicidal behavior, gestures, or threats, or self-mutilating behavior" predicts future SAa could cause a tautological increase in the predictive value of borderline PD for future attempts. However, in a sensitivity analysis, whether or not the suicide item was included in the diagnosis had no influence on our findings. Ninth, we cannot exclude the possibility that some personality traits not fully captured by the DSM PD constructs, e.g. impulsive or nonimpulsive aggressive traits (Dalca et al., 2013; Keilp et al., 2006; Mann et al., 2009; McGirr et al., 2008) might have important moderating effects on risk for suicidal acts. Thus, a study of the influence of clinical PDs is not a full account of the impact of all personality traits. Finally, it is important to understand the nature of the cohorts investigated; we investigated the influence of PDs on SAs among psychiatric care patients with unipolar and bipolar major mood disorders and among primary care patients with depressive disorders. Generalizability of findings to patients with PDs without mood disorders, or to completed suicides among patients with mood disorders, not to speak of other patients, requires further confirmation.

Diagnosis of any comorbid PD was associated with an approximately two-fold rate of both lifetime SAs and new (prospectively observed) SAs among mood disorder patients, in agreement with earlier studies (Bolton et al., 2010; Undurraga et al., 2012). However, after adjustment for time spent in MDEs, all of the associations, except those with cluster C PDs, were attenuated and became non-significant. Thus, the influence of comorbid PD on the rate of new SAs is mostly mediated by the time spent in high-risk state, i.e. in MDEs. This is consistent with our previous study, where the influence of an individual's temperament and character on suicide attempt risk was mediated by the time spent in MDEs (Jylha et al., in Press). Thus, irrespective of whether the variation in personality is conceptualized as a trait dimension or a diagnostic category, its impact is mostly mediated by an associated predisposition to spend extended periods in depressive states, which then carry a high risk for suicidal acts.

A small and rarely discussed minority of individuals with mood disorders suffer from cluster A PDs. We found that also these PDs increased the rate of prospectively evaluated new SAs, even after adjusting for age, gender, sampling cohort, and previous SAs. This is in accord with a previous study (Bolton et al., 2010) in which schizoid, paranoid, and schizotypal PDs were associated with future SA. However, our finding was non-significant in bipolar patients, and was attenuated by adjusting for the generally weaker social support among these patients, and only half of that total effect was mediated by the time spent in MDE. Nevertheless, time spent in MDEs during the follow-up mediated the effects of cluster A PDs on the rate of new SAs. Overall, increased risk of SAs among mood disorder patients with cluster A PDs is likely to be due to multiple reasons, including increased time depressed, weaker social support, and direct effects of the PD when depressed. Whether or not the cognitive distortions typical for these patients influence the risk remains unknown.

Cluster B and borderline PDs increased the rate of lifetime and new SAs. This was expected and fully in line with earlier studies (Bolton et al., 2010; Soloff and Chiappetta, 2012; Soloff and Fabio, 2008; Yen et al., 2003). Of separate DSM-IV borderline PD criteria only identity disturbance predicted new SAs after adjusting for age, sex, having had a previous suicide attempt, and number of previous attempts. This finding is in contrast to an earlier study (Yen et al., 2004), in which affective instability most strongly associated with suicidal behavior. In our analysis, the effect of Cluster $\mathrm{B}$ and borderline PD on both the rate and probability of new SAs was clearly found to be mediated by the time spent in MDEs. While this is concordant with findings of the US NESARC study (Skodol et al., 2011), we nevertheless also expected a major riskmodifying effect when depressed. Three factors may have influenced our findings. First, while we deliberately included mood disorder patients with all types of comorbid disorders in the cohorts, patients with substance-induced mood episodes were not included. Thus, some of the borderline PD patients most at risk for suicidal behavior were possibly excluded, and those included were likely less substance-abusing than borderline patients at large. Second, the mean age of about 40 years in the mood disorder cohorts differs from most cohort studies of borderline PD, which mostly involve young adults. Therefore, the clinical profile of our patients was likely also different, reflecting later phases in the course of PDs. Third, in the absence of specialized services for patients with borderline PD at the time of data collection, highly impulsive patients may have visited psychiatric settings only briefly at times of crisis and might thus have been less likely to be included in the two psychiatric cohorts. Therefore, while our findings provide evidence for the risk-increasing role of borderline PD because of more time spent depressed, they do not negate the findings of studies determining other aspects of borderline psychopathology to be important.

Cluster C PDs are generally not perceived to markedly contribute to the risk of suicidal acts. However, we found them to play an important role among mood disorder patients due to their strong influence on chronicity and recurrences of unipolar and bipolar mood disorders (Holma et al., 2008; Pallaskorpi et al., 2015), and the associated increase in the rate of lifetime and prospectively evaluated new SAs. This impact of comorbid cluster C PDs (that is not found with comorbid cluster B PDs) on the increased risk of SAs might be due to other common underlying risk factors affecting on chronicity and recurrences of mood disorders e.g. personality traits (Rosenström et al., 2014) or low level of social support (Leskelä et al., 2004). In line with our finding, new SAs were also found to be associated with cluster C PDs in a previous study (Oleski et al., 2012). Moreover, even during the high-risk period of MDE, cluster C PDs nearly doubled the SA rate. It is possible that the influence on risk of suicidal acts varies depending on the specific PD. In post-hoc analyses, we found that during the total follow-up cluster C, avoidant, and dependent PDs, but not obsessive-compulsive PD, increased the rate of new SAs by $165 \%$. Moreover, the number of symptoms for avoidant PD had a rough dose-response relationship with the rate of new SAs. About half of the effect of cluster C PDs on the rate of new SAs, and about 2/3 of the effect on the probability of making at least one SA, was mediated by the time spent in MDEs. Thus, cluster C PDs seem to have an effect on SAs both by increasing time at risk and by increasing risk when depressed.

In conclusion, among mood disorder patients, comorbid PDs increase the risk of SAs by approximately two-fold. The excess risk is mostly due to the finding that patients with comorbid PDs spend more time in depressive episodes than those without comorbid PDs. Consequently, the risk was highest for PDs that most strongly predispose to more time depressed. This putative causal pathway has important clinical implications because MDEs are treatable. However, direct risk-modifying effects of PDs are also likely to exist. 


\section{Conflict of interest}

Dr. Oquendo has received royalties from the commercial use of the C-SSRS. Her family owns stock in Bristol Myers Squibb. All other authors declare no conflicts of interest.

\section{Acknowledgments}

Financial support: This work was supported by the Academy of Finland (E.I.) (L.K-J., Grant number 258711) and the Department of Psychiatry at Helsinki University Central Hospital (E.I.).

\section{Appendix A. Supplementary material}

Supplementary data associated with this article can be found in the online version at http://dx.doi.org/10.16/j.jad.2015.11.006.

\section{References}

APA (American Psychiatric Association), 2003. Practice guideline for the assessment and treatment of patients with suicidal behaviours. Am. J. Psychiatry 160 (November suppl).

Beck, A.T., Epstein, N., Brown, G., Steer, R.A., 1988. An inventory for measuring clinical anxiety: psychometric properties. J. Consult. Clin. Psychol. 56, 893-897.

Beck, A.T., Schuyler, D., Herman, I., 1974. Development of suicidal intent scales. In: Beck, A.T., Resnik, H.L.P., Lettieri, D.J. (Eds.), The Prediction of Suicide. Charles Press, Philadelphia, PA, pp. 45-56.

Beck, A.T., Ward, C.H., Mendelson, M., Mock, J., Erbaugh, J., 1961. An inventory for measuring depression. Arch. Gen. Psychiatry 4, 561-571.

Beghi, M., Rosenbaum, J.F., Cerri, C., Cornaggia, C.M., 2013. Risk factors for fatal and nonfatal repetition of suicide attempts: a literature review. Neuropsychiatr. Dis. Treat. 9, 1725-1736.

Bolton, J.M., Pagura, J., Enns, M.W., Grant, B., Sareen, J., 2010. A population-based longitudinal study of risk factors for suicide attempts in major depressive disorder. J. Psychiatr. Res. 44, 817-826.

Cameron, A.C., Trivedi, P.K., 1990. Regression-based tests for overdispersion in the Poisson model. J. Econ. 46, 347-364.

Cavanagh, J.T., Carson, A.J., Sharpe, M., Lawrie, S.M., 2003. Psychological autopsy studies of suicide: a systematic review. Psychol. Med. 33, 395-405.

Cheng, A.T., Mann, A.H., Chan, K.A., 1997. Personality disorder and suicide. A casecontrol study. Br. J. Psychiatry 170, 441-446.

Dalca, I.M., McGirr, A., Renaud, J., Turecki, G., 2013. Gender-specific suicide risk factors: a case-control study of individuals with major depressive disorder. J. Clin. Psychiatry 74, 1209-1216.

First, M., Spitzer, R.L., Gibbon, M., Williams, J.B., 2002. Structured Clinical Interview for DSM-IV-TR Axis I Disorders. New York State Psychiatric Institute, New York (Research Version, Patient Edition With Psychotic Screen. Biometrics Research).

First, M.B., Spitzer, R.I., Gibbon, M., Williams, J.B.W., 1997. Structured Clinical Interview for DSM-IV Personality Disorders (SCID-II). American Psychiatric Press, Inc, Washington, DC.

Foster, T., Gillespie, K., McClelland, R., 1997. Mental disorders and suicide in Northern Ireland. Br. J. Psychiatry 170, 447-452.

Galfalvy, H., Oquendo, M.A., Carballo, J.J., Sher, L., Grunebaum, M.F., Burke, A., Mann, J.J., 2006. Clinical predictors of suicidal acts after major depression in bipolar disorder: a prospective study. Bipolar Disord. 8, 586-595.

Hamilton, M., 1960. A rating scale for depression. J. Neurol. Neurosurg. Psychiatry 23, 56-62.

Hawton, K., Casanas, I.C.C., Haw, C., Saunders, K., 2013. Risk factors for suicide in individuals with depression: a systematic review. J. Affect. Disord. 147, 17-28.

Henriksson, M.M., Aro, H.M., Marttunen, M.J., Heikkinen, M.E., Isometsä, E.T., Kuoppasalmi, K.I., Lönnqvist, J.K., 1993. Mental disorders and comorbidity in suicide. Am. J. Psychiatry 150, 935-940.

Holma, K.M., Haukka, J., Suominen, K., Valtonen, H.M., Mantere, O., Melartin, T.K. Sokero, T.P., Oquendo, M.A., Isometsa, E.T., 2014. Differences in incidence of suicide attempts between bipolar I and II disorders and major depressive disorder. Bipolar Disord. 16, 652-661.

Holma, K.M., Holma, I.A., Melartin, T.K., Rytsala, H.J., Isometsa, E.T., 2008. Long-term outcome of major depressive disorder in psychiatric patients is variable. J. Clin. Psychiatry 69, 196-205.

Holma, K.M., Melartin, T.K., Haukka, J., Holma, I.A., Sokero, T.P., Isometsa, E.T. 2010. Incidence and predictors of suicide attempts in DSM-IV major depressive disorder: a five-year prospective study. Am. J. Psychiatry 167, 801-808.

Imai, K., Keele, L., Tingley, D., 2010. A general approach to causal mediation analysis. Psychol. Methods 15, 309-334.

Isometsa, E., 2014. Suicidal behaviour in mood disorders-who, when, and why? Can. J. Psychiatry 59, 120-130.

Jylha, P., Rosenström, T., Mantere, O., Suominen, K., Melartin, T., Vuorilehto, M., Holma, M., Riihimaki, K., Oquendo, M., Keltikangas-Järvinen, L., Isometsa, E. 2015. Temperament, character and suicide attempts in unipolar and bipolar mood disorders. J. Clin. Psychiatry (In Press).

Keilp, J.G., Gorlyn, M., Oquendo, M.A., Brodsky, B., Ellis, S.P., Stanley, B., John Mann,
J., 2006. Aggressiveness, not impulsiveness or hostility, distinguishes suicide attempters with major depression. Psychol. Med. 36, 1779-1788.

Leskelä, U., Melartin, T., Lestelä-Mielonen, P., Rytsälä, H., Sokero, P., Heikkinen, M., Isometsä, E., 2004. Life events, social support, and onset of major depressive episode in Finnish patients. J. Nerv. Ment. Dis. 192, 373-381.

Mann, J.J., Arango, V.A., Avenevoli, S., Brent, D.A., Champagne, F.A., Clayton, P., Currier, D., Dougherty, D.M., Haghighi, F., Hodge, S.E., Kleinman, J., Lehner, T., McMahon, F., Moscicki, E.K., Oquendo, M.A., Pandey, G.N., Pearson, J., Stanley, B., Terwilliger, J., Wenzel, A., 2009. Candidate endophenotypes for genetic studies of suicidal behavior. Biol. Psychiatry 65, 556-563.

Mann, J.J., Waternaux, C., Haas, G.L., Malone, K.M., 1999. Toward a clinical model of suicidal behavior in psychiatric patients. Am. J. Psychiatry 156, 181-189.

Mantere, O., Suominen, K., Leppamaki, S., Valtonen, H., Arvilommi, P., Isometsa, E., 2004. The clinical characteristics of DSM-IV bipolar I and II disorders: baseline findings from the Jorvi Bipolar Study (JoBS). Bipolar Disord. 6, 395-405.

Mantere, O., Suominen, K., Valtonen, H.M., Arvilommi, P., Leppamaki, S., Melartin, T., Isometsa, E., 2008. Differences in outcome of DSM-IV bipolar I and II disorders. Bipolar Disord. 10, 413-425.

McGirr, A., Renaud, J., Bureau, A., Seguin, M., Lesage, A., Turecki, G., 2008. Impulsive-aggressive behaviours and completed suicide across the life cycle: a predisposition for younger age of suicide. Psychol. Med. 38, 407-417.

Melartin, T.K., Rytsälä, H.J., Leskelä, U.S., Lestelä-Mielonen, P.S., Sokero, T.P., Isometsä, E.T., 2002. Current comorbidity of psychiatric disorders among DSM-IV major depressive disorder patients in psychiatric care in the Vantaa Depression Study. J. Clin. Psychiatry 63, 126-134.

Nordentoft, M., Mortensen, P.B., Pedersen, C.B., 2011. Absolute risk of suicide after first hospital contact in mental disorder. Arch. Gen. Psychiatry 68, 1058-1064.

Oleski, J., Cox, B.J., Robinson, J., Grant, B., 2012. The predictive validity of Cluster C personality disorders on the persistence of major depression in the national epidemiologic survey on alcohol and related conditions. J. Pers. Disord. 26, 322-333.

Oquendo, M.A., Bongiovi-Garcia, M.E., Galfalvy, H., Goldberg, P.H., Grunebaum, M.F., Burke, A.K., Mann, J.J., 2007. Sex differences in clinical predictors of suicidal acts after major depression: a prospective study. Am. J. Psychiatry 164, 134-141.

Pallaskorpi, S., Suominen, K., Ketokivi, M., Mantere, O., Arvilommi, P., Valtonen, H. Leppamaki, S., Isometsa, E., 2015. Five-year outcome of bipolar I and II disorders: findings of the Jorvi Bipolar Study. Bipolar Disord. 17, 363-374.

Riihimaki, K., Vuorilehto, M., Melartin, T., Haukka, J., Isometsa, E., 2014a. Incidence and predictors of suicide attempts among primary-care patients with depressive disorders: a 5-year prospective study. Psychol. Med. 44, 291-302.

Riihimaki, K.A., Vuorilehto, M.S., Melartin, T.K., Isometsa, E.T., 2014b. Five-year outcome of major depressive disorder in primary health care. Psychol. Med. 44 1369-1379 (Epub 2011 Nov 16).

Rosenström, T., Jylhä, P., Cloninger, C.R., Hintsanen, M., Elovainio, M., Mantere, O., Pulkki-Råback, L., Riihimäki, K., Vuorilehto, M., Keltikangas-Järvinen, L., Isometsä, E., 2014. Temperament and character traits predict future burden of depression. J. Affect. Disord. 158, 139-147.

Skodol, A.E., Grilo, C.M., Keyes, K.M., Geier, T., Grant, B.F. Hasin, D.S., 2011. Relationship of personality disorders to the course of major depressive disorder in a nationally representative sample. Am. J. Psychiatry 168, 257-264.

Soloff, P.H., Chiappetta, L., 2012. Prospective predictors of suicidal behavior in borderline personality disorder at 6-year follow-up. Am. J. Psychiatry 169, 484-490.

Soloff, P.H., Fabio, A., 2008. Prospective predictors of suicide attempts in borderline personality disorder at one, two, and two-to-five year follow-up. J. Pers. Disord. 22, 123-134.

Stringer, B., van Meijel, B., Eikelenboom, M., Koekkoek, B., Licht, C.M., Kerkhof, A.J., Penninx, B.W., Beekman, A.T. 2013. Recurrent suicide attempts in patients with depressive and anxiety disorders: the role of borderline personality traits. J. Affect. Disord. 151, 23-30.

Undurraga, J., Baldessarini, R.J., Valenti, M., Pacchiarotti, I., Vieta, E., 2012. Suicidal risk factors in bipolar I and II disorder patients. J. Clin. Psychiatry 73, 778-782.

Valtonen, H.M., Suominen, K., Haukka, J., Mantere, O., Leppamaki, S., Arvilommi, P., Isometsa, E.T., 2008. Differences in incidence of suicide attempts during phases of bipolar I and II disorders. Bipolar Disord. 10, 588-596.

van Buuren, S., Groothuis-Oudshoorn, K., 2011. mice: Multivariate imputation by chained equation in R. J. Stat. Softw. 45, 1-67.

Wing, J.K., Babor, T., Brugha, T., Burke, J., Cooper, J.E., Giel, R., Jablenski, A., Regier, D., Sartorius, N., 1990. SCAN: schedules for clinical assessment in neuropsychiatry. Arch. Gen. Psychiatry 47, 589-593.

Vuorilehto, M., Melartin, T., Isometsä, E., 2005. Depressive disorders in primary care: recurrent, chronic, and co-morbid. Psychol. Med. 35, 673-682.

Vuorilehto, M.S., Melartin, T.K., Isometsa, E.T., 2009. Course and outcome of depressive disorders in primary care: a prospective 18-month study. Psychol. Med. 39, 1697-1707.

Yen, S., Shea, M.T., Pagano, M., Sanislow, C.A., Grilo, C.M., McGlashan, T.H., Skodol, A.E., Bender, D.S., Zanarini, M.C., Gunderson, J.G., Morey, L.C., 2003. Axis I and axis Il disorders as predictors of prospective suicide attempts: findings from the collaborative longitudinal personality disorders study. J. Abnorm Psychol. 112, 375-381.

Yen, S., Shea, M.T., Sanislow, C.A., Grilo, C.M., Skodol, A.E., Gunderson, J.G., McGlashan, T.H., Zanarini, M.C., Morey, L.C., 2004. Borderline personality disorder criteria associated with prospectively observed suicidal behavior. Am. J. Psychiatry $161,1296-1298$.

Young, R.C., Biggs, J.T., Ziegler, V.E., Meyer, D.A., 1978. A rating scale for mania: reliability, validity and sensitivity. Br. J. Psychiatry 133, 429-435. 